\title{
Article \\ Tadalafil Treatment of Mice with Fetal Growth Restriction and Preeclampsia Improves Placental mTOR Signaling
}

\author{
Kayo Tanaka (D), Hiroaki Tanaka *(D), Ryota Tachibana, Kento Yoshikawa, Takuya Kawamura, Sho Takakura, \\ Hiroki Takeuchi (D) and Tomoaki Ikeda (D)
}

Department of Obstetrics and Gynecology, Mie University School of Medicine, Edobashi, Tsu 5148507, Mie, Japan; tanaka-ky@clin.medic.mie-u.ac.jp (K.T.); r-tachibana@clin.medic.mie-u.ac.jp (R.T.);

yoshikawa-k@clin.medic.mie-u.ac.jp (K.Y.); kwmrtky1112@yahoo.co.jp (T.K.);

s-takakura@clin.medic.mie-u.ac.jp (S.T.); h-takeuchi@clin.medic.mie-u.ac.jp (H.T.);

t-ikeda@clin.medic.mie-u.ac.jp (T.I.)

* Correspondence: h_tanaka@med.miyazaki-u.ac.jp; Tel.: +81-59-232-1111; Fax: +81-59-231-5202

Citation: Tanaka, K.; Tanaka, H.; Tachibana, R.; Yoshikawa, K.;

Kawamura, T.; Takakura, S.;

Takeuchi, H.; Ikeda, T. Tadalafil Treatment of Mice with Fetal

Growth Restriction and

Preeclampsia Improves Placental

mTOR Signaling. Int. J. Mol. Sci. 2022,

23, 1474. https:// doi.org/10.3390/

ijms23031474

Academic Editor: Antonios

N. Gargalionis

Received: 26 December 2021

Accepted: 26 January 2022

Published: 27 January 2022

Publisher's Note: MDPI stays neutral with regard to jurisdictional claims in published maps and institutional affiliations.

Copyright: (C) 2022 by the authors. Licensee MDPI, Basel, Switzerland. This article is an open access article distributed under the terms and conditions of the Creative Commons Attribution (CC BY) license (https:// creativecommons.org/licenses/by/ $4.0 /)$.

\begin{abstract}
Fetal growth restriction (FGR) is a major cause of poor perinatal outcomes. Although several studies have been conducted to improve the prognosis of FGR in infants, no effective intrauterine treatment method has been established. This study aimed to use tadalafil, a phosphodiesterase 5 inhibitor (PDE5) inhibitor, as a novel intrauterine treatment and conducted several basic and clinical studies. The study investigated the effects of tadalafil on placental mTOR signaling. Tadalafil was administered to mice with L-NG-nitroarginine methyl ester (L-NAME)-induced FGR and associated preeclampsia (PE). Placental phosphorylated mTOR (p-mTOR) signaling was assessed by fluorescent immunohistochemical staining and Western blotting. The expression of $\mathrm{p}$-mTOR was significantly decreased in mice with FGR on 13 days post coitum (d.p.c.) but recovered to the same level as that of the control on 17 d.p.c. following tadalafil treatment. The results were similar for 4E-binding protein 1 (4E-BP1) and S6 ribosomal (S6R) protein, which act downstream in the mTOR signaling pathway. We demonstrate that the tadalafil treatment of FGR in mice improved placental mTOR signaling to facilitate fetal growth. Our study provides the key mechanistic detail about the mode of action of tadalafil and thus would be helpful for future clinical studies on FGR.
\end{abstract}

Keywords: fetal growth restriction; placenta; mTOR signaling; tadalafil; preeclampsia; L-NAME

\section{Introduction}

Fetal growth restriction (FGR) is a major cause of poor perinatal outcomes [1,2]. At present, there is no effective intrauterine treatment for FGR, and children with FGR not only have a high perinatal mortality rate but also remain at risk for poor neurological prognosis even if they survive $[3,4]$. Although many studies have been conducted to improve the prognosis of FGR in infants, no effective intrauterine treatment method has been established. Moreover, studies have explored when to terminate a pregnancy; however, no standardized method to improve the prognosis has been identified $[5,6]$.

The efficiency of tadalafil, a phosphodiesterase 5 inhibitor (PDE5) inhibitor, to treat FGR is evident [7-11]. However, the exact mechanism of its action remains elusive. Therefore, we focused on the mammalian target of rapamycin (mTOR), one of the major regulatory factors associated with fetal growth, particularly mTOR complex1 signaling, to clarify the mechanism of action of tadalafil in the FGR placenta. Tadalafil inhibits PDE5 in smooth muscle cells, thereby inhibiting the degradation of local cGMP, which relaxes smooth muscle cells. This increases uteroplacental blood flow and placental oxygenation, facilitating the growth of the fetus. We have also shown that in mice, tadalafil dilates the maternal vascular sinuses of the placenta and improves hypoxic changes in the placenta [7]

Mechanistic target of rapamycin (mTOR) signaling in the placenta plays an important role in fetal growth and development, and its dysregulation may lead to miscarriage [12]. 
mTOR, a serine/threonine kinase, is highly expressed in syncytiotrophoblasts of the human placenta [13]. It senses various signals such as growth factors, amino acids, and stress from intracellular and extracellular sources and regulates cell growth, metabolic activity, and survival [14-18]. mTOR forms two intracellular complexes, mTOR complex (mTORC)1 and mTORC2, both expressed in the placenta. mTORC1 promotes protein translation through the phosphorylation of S6 Kinase 1 (S6K1) and 4E-binding protein 1 (4E-BP1) and is mainly involved in regulating cell growth and metabolism [14-19], whereas mTORC2 plays an important role in cell proliferation and survival. Furthermore, mTORC1 acts as a placental nutrient sensor indirectly by regulating trophoblast ATP production, which is critical for protein synthesis and energy-intensive active transport in the placenta [20]. Recently, it has been shown that mTOR signaling "directly" regulates nutrient transport from the maternal circulation to the placenta [13,21-25]. Furthermore, several studies based on the phosphorylation of key downstream targets of mTOR have shown that mTOR signaling activity is suppressed in the human FGR placenta [26-29]. Therefore, we hypothesized that assessing the effects of tadalafil on mTOR signaling activity in the FGR placenta could provide insights into understanding its therapeutic effect on FGR and the underlying mechanism of action.

The purpose of this study was to evaluate the effect of tadalafil on mTORC1 signaling activity in the FGR placenta. Furthermore, to understand its mechanism of action, we investigated the expression of two key target proteins, 4E-BP1 and S6 ribosomal protein (S6R), the key downstream targets of mTORC1 signaling. This study will improve the key mechanistic detail about the mode of action of the beneficial effects of tadalafil on FGR, and thus will be helpful for future clinical studies on FGR.

\section{Results}

\subsection{Expression of Phosphorylated mTOR ( $p$-mTOR) in Mice Placenta}

\subsubsection{Placental p-mTOR Expression on 13 Days Post Coitum (d.p.c.)}

To analyze the effect of L-NG-nitroarginine methyl ester (L-NAME)-induced FGR and associated preeclampsia (PE) on p-mTOR signaling in the placenta, we performed fluorescent immunohistochemical staining using anti-phospho-mTOR (Ser2448) antibody on 13 d.p.c. (Figure 1). The percentage area expressing p-mTOR in the labyrinth zone of mouse placenta was $13.8 \pm 1.97 \%$ in L-NAME mice $(\mathrm{L})$ and $45.1 \pm 3.28 \%$ in control mice (C), which was significantly lower in Group L $(p<0.05)$.

A

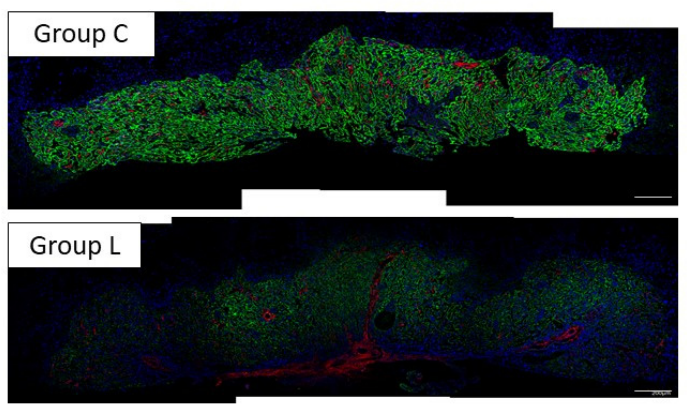

B

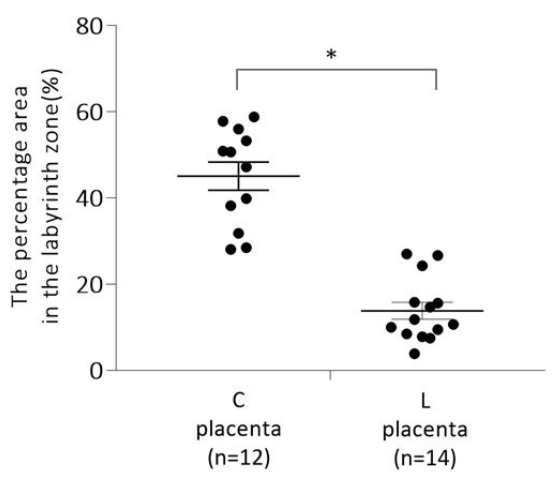

Figure 1. Expression of phosphorylated mechanistic target of rapamycin (p-mTOR) (Ser2448) in the placentas on 13 d.p.c. Paraformaldehyde-fixed, paraffin-embedded placental tissues were used to confirm the expression of p-mTOR by fluorescent immunohistochemical staining. (A) Representative images of p-mTOR (Ser2448) expression (green) in group C (upper panel) and group L (lower panel). (B) The percentage of p-mTOR (Ser2448)-positive area in control and L-NAME placenta. Data are expressed as the mean \pm standard error (SE). Group C, control mice; Group L, L-NAME-induced FGR mice. ${ }^{*} p<0.05$. 


\subsubsection{Placental p-mTOR Expression on 17 d.p.c}

Further, we subjected the placenta of mice treated with L-NAME and tadalafil (Group LT) to immuno-histochemical analysis on 17 d.p.c. (Figure 2). The percentage area with p-mTOR expression in the labyrinth zone of mice placenta was $58.5 \pm 2.51 \%$ in control mice (C), $32.2 \pm 3.52 \%$ in L-NAME mice (L), and $52.4 \pm 3.07 \%$ in L-NAME-tadalafil mice (LT). Similar to the results on 13 d.p.c., p-mTOR expression in Group L was significantly lower $(p<0.01)$ than that of Group C, but its expression in Group LT was not significantly different from that of Group C. In addition, the percentage of area expressing p-mTOR was significantly higher in Group LT than in Group L $(p<0.05)$.

A

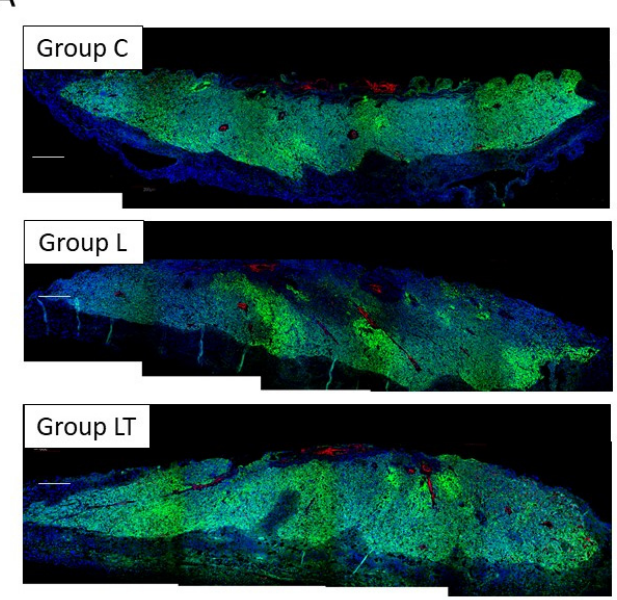

B

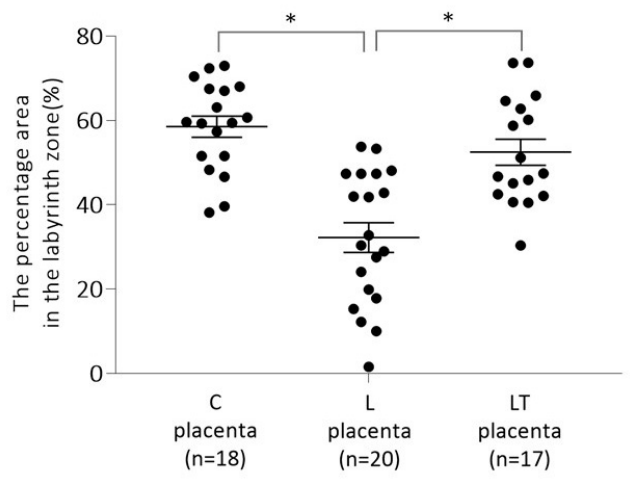

Figure 2. Expression of p-mTOR (Ser2448) in the placentas on 17 d.p.c. Paraformaldehyde-fixed, paraffin-embedded placental tissues were used to confirm the expression of p-mTOR by fluorescent immunohistochemical staining. (A) Representative images of p-mTOR (Ser2448) expression (shown in green) in group C (upper panel), group L (middle panel), and group LT (lower panel). (B) The percentage of p-mTOR (Ser2448)-positive area in three groups. Data are expressed as mean $\pm \mathrm{SE}$. Group C, control mice; Group L, L-NAME-induced FGR mice without tadalafil treatment; Group LT, L-NAME-induced FGR mice with tadalafil treatment. ${ }^{*} p<0.05$.

2.2. Expression Analysis of Phosphorylated 4E (eIF4E)-Binding Protein 1 ( $p-4 E-B P 1)$ and Phosphorylated Ribosomal S6 Protein ( $p$-S6R) in Mouse Placenta

2.2.1. 4E-BP1 and S6R Expression in Placenta on 13 d.p.c.

Next, we investigated the expression of 4E-BP1 and S6R, the downstream signaling proteins of mTORC1, a functional partner of mTOR. The results are shown in Figure 3. The expression level of 4E-BP1 total protein was not significantly different between the two groups (102.2 $\pm 2.9 \%$ in Group C and $109.0 \pm 12.1 \%$ in Group L); however, the expression of its phosphorylated form, p-4E-BP1 (Thr37/46) was significantly lower in Group L $(58.1 \pm 8.6 \%)$ than that in Group C $(81.1 \pm 16.4 \%)(p<0.05)$.

Similarly, total S6R protein expression was not significantly different between the two groups (95.1 $\pm 26.0 \%$ in Group C and $88.4 \pm 31.6 \%$ in Group L). However, p-S6R (Ser235/236) expression was significantly lower in Group L (58.1 $\pm 8.6 \%)$ than in Group C $(81.1 \pm 16.4 \%)(p<0.05)$. 
A

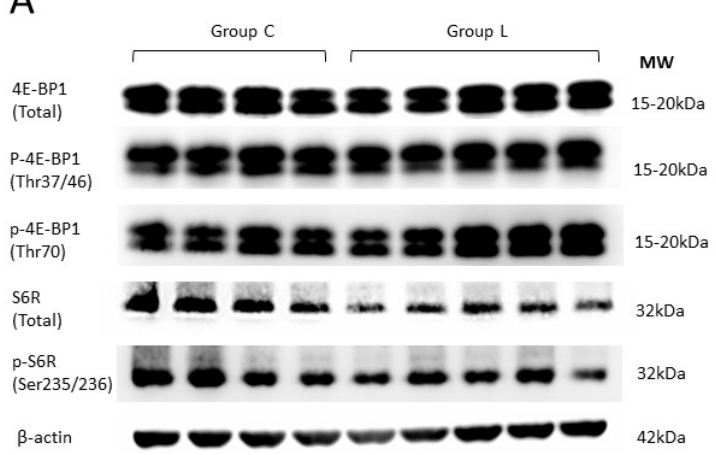

B

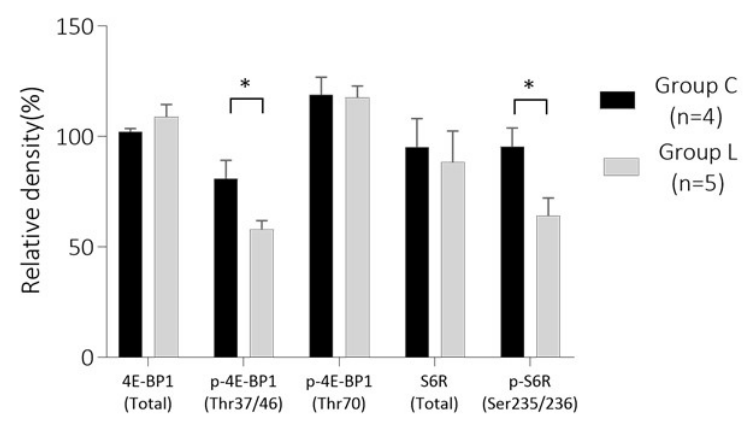

Figure 3. Expression analysis of key downstream targets of mTOR complex 1 (mTORC1) signaling; 4E-BP1 and S6R in the placenta on 13 d.p.c. (A) Representative Western blot images of each target. (B) Comparison of relative density between Group C and Group L. Data represent the mean $\pm \mathrm{SE}$. Group C, control mice; Group L, L-NAME-induced FGR mice; 4E-BP1, eIF4E-binding protein 1; S6R, ribosomal S6 protein; MW, molecular weight. * $p<0.05$.

\subsubsection{E-BP1 and S6R Expression in Placenta on 17 d.p.c.}

We tested the effect of tadalafil treatment on mTORC1 downstream signaling on 17 d.p.c. As shown in Figure 4, the expression of 4E-BP1 (total) and S6R (total) was not significantly different between the three groups [Groups C $(n=5), \mathrm{L}(n=5)$, and LT $(n=7)]$. However, expression levels of p-4E-BP1 and p-S6R decreased significantly in Group L compared with those in Group C, which was restored by tadalafil treatment in Group LT. The mean \pm SE obtained for each dataset was as follows: p-4E-BP1(Thr37/46): $91.6 \pm 10.4 \%, 68.1 \pm 15.3 \%$, and $97.0 \pm 22.2 \%$; p-4E-BP1(Thr70): $84.5 \pm 19.5 \%, 58.4 \pm 9.6$, and $75.0 \pm 14.1 \%$; p-S6R (Ser235/236): $90.6 \pm 18.3 \%, 56.3 \pm 10.7 \%$, and $85.0 \pm 24.0 \%$ in Groups C, L, and LT, respectively.

\section{A}

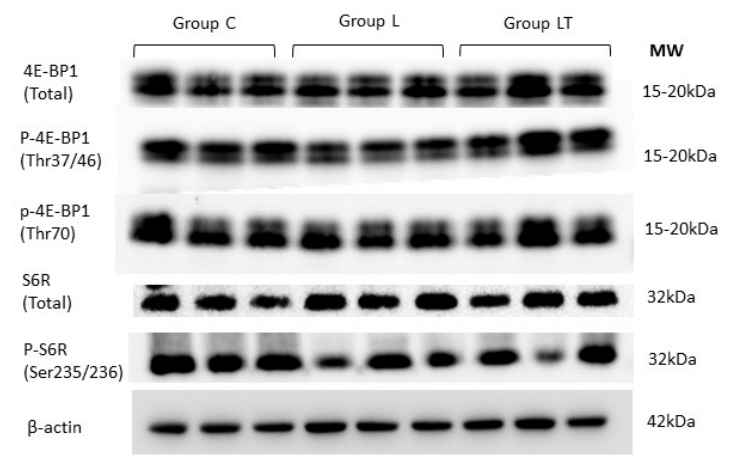

B

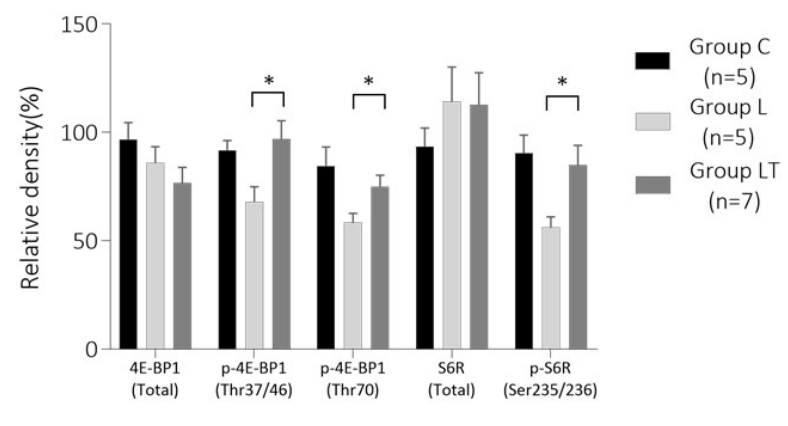

Figure 4. Expression analysis of key downstream targets of mTORC1 signaling; 4E-BP1 and S6R in the placenta on 17 d.p.c. (A) Representative Western blot images of each target. (B) Comparison of relative density among the three groups (Groups $\mathrm{C}, \mathrm{L}$, and LT). Data represent the mean $\pm \mathrm{SE}$. Group C, control mice; Group L, L-NAME-induced FGR mice; 4E-BP1, eIF4E-binding protein 1; S6R, ribosomal S6 protein; MW, molecular weight. * $p<0.05$.

\section{Discussion}

In the present study, we investigated mTOR signaling in the placenta of the L-NAMEinduced FGR and PE mouse model. In the syncytiotrophoblast of the placenta, mTOR forms mTORC1 in association with several other metabolic signals [30]. mTORC1 regulates metabolism, growth, cell division, and cell death in response to growth factors, such as insulin and insulin-like growth factor-1 (IGF-1), intracellular ATP levels, hypoxia, DNA damage, biomolecules such as amino acids, glucose, and fatty acids. It plays a central role 
in the regulation of growth, cell division, and cell death. It has also been reported that placental mTORC1 regulates active transport via nutrition transporters and mitochondrial function [20], and its activity has been shown to be suppressed in FGR [26-29]. These studies indicate that mTOR signaling plays a pivotal role in fetal growth and development.

This study investigated the effect of an FGR inducer, L-NAME, and FGR suppressor, tadalafil, on mTOR signaling. We further tested the expression of two key target proteins, 4E-BP1 and S6R, which act downstream in the mTORC1 signaling pathway. On 13 d.p.c., L-NAME administration significantly decreased the expression of p-mTOR (Ser2448), p4E-BP1 (Thr37/47), and p-S6R (Ser235/236) in the mouse placenta, indicating that mTOR signaling activity was suppressed. In contrast, tadalafil treatment restored expression of all the three proteins to the same level as that of the control group on 17 d.p.c. Therefore, we concluded that tadalafil treatment restored mTOR signaling, which was suppressed in the L-NAME-induced FGR placenta. Concordantly, several previous studies have reported the suppression of mTORC1 signaling activity in the FGR mouse model [26,28,31,32].

We previously reported that the administration of tadalafil to the L-NAME-induced FGR mouse model facilitates fetal development [7]. Therefore, we used the L-NAMEinduced FGR model for studying the effects of tadalafil on mTOR signaling. Our previous study demonstrated that the effect of tadalafil on fetal growth is modulated via improved placental hypoxia [7]. As tadalafil has a vasodilator effect by enhancing cGMP levels in vascular smooth muscle cells, the study inferred that it improves fetal placental blood circulation by dilating uterine arteries, leading to subsequent improvement of hypoxia and mTOR signaling in the placenta of tadalafil-treated mice. However, there is enough evidence to suggest that tadalafil may not act through the uterine artery dilation route alone [9]. For example, in our previous study, tadalafil administered to a reduced uterine perfusion pressure (RUPP) mouse model demonstrated a fetal growth effect [9]. In the RUPP mouse model, PE and FGR were induced in the pregnant mouse by ligating the ovarian and uterine arteriovenous arteries with a nylon thread, which reduces uterine pressure $[33,34]$. In this RUPP mouse model, although fetal growth was improved, the uterine artery diameter did not change with tadalafil treatment, suggesting the possibility of a direct effect of tadalafil rather than through uterine artery dilation. Furthermore, tadalafil also has ameliorating effects on vascular endothelial damage in addition to antiinflammatory and antioxidant effects $[9,35,36]$. Therefore, it can be expected that the improvement in mTOR signaling activity in the present study could also be modulated via some of these direct effects of tadalafil.

In addition to tadalafil, other PDE5 inhibitors include sildenafil and vardenafil, which differ mainly for their time to effect, half-life, and PDE selectivity [37-39]. Tadalafil is 187 times more selective for PDE5 than PDE6, whereas it is significantly less selective for PDE11 A ( 5 times more selective for PDE5 than for PDE11 A) [40]. Although several clinical studies of sildenafil treatment for FGR have been conducted in several countries, reports on its efficacy are scarce [41-43]. Furthermore, tadalafil has been shown to have a different effect on pulmonary hypertension than sildenafil [38], indicating the clinical significance of the effect of tadalafil on FGR as well. Therefore, the results of this study may support future clinical studies.

This study is limited by the fact that it was restricted to a single mouse model of L-NAME-induced FGR and associated PE. In this study, we have shown that tadalafil alters mTOR signaling to facilitate fetal development via enhanced fetal placental circulation in the placenta. However, it is important to elucidate further the detailed mechanism of action of tadalafil and to ascertain its role on mTOR signaling in FGR and PE treatment through clinical studies.

\section{Materials and Methods}

This study was conducted under the review and approval of the Mie University Animal Experiment Committee (Approval code 273111 and date of approval: 1 May 2020). 


\subsection{Establishment of FGR Mouse Model and Experimental Protocol}

We have previously established a mouse model of FGR with PE in which the dams exhibited hypertension and proteinuria, and the fetus exhibited growth restriction when the nitric oxide synthase inhibitor L-NAME (Cayman Chemical, Ann Arbor, MI, USA) was administered to pregnant mothers. FGR was induced in C57BL/6 pregnant mice by administering L-NAME solution at a concentration of $1 \mathrm{mg} / \mathrm{mL}$ starting 11 d.p.c. [7] The average dose of L-NAME was $280.9 \pm 22.5 \mathrm{mg} / \mathrm{kg}$ bodyweight (BW)/day.

Twenty pregnant C57BL/ 6 dams (CLEA Japan, Tokyo, Japan) were purchased on 9 d.p.c. and divided into two groups based on their matching weight and blood pressure: a control group (Group C, $n=6$ ), which received $0.5 \%$ carboxymethyl-cellulose (CMC; Wako Pure Chemical Industries, Osaka, Japan) dissolved in drinking water on 11 d.p.c and L-NAME-treated group (Group L, $n=14$ ) received dissolved in $0.5 \% \mathrm{CMC}$ and $1 \mathrm{mg} / \mathrm{mL}$ L-NAME (Cayman Chemical) starting on 11 d.p.c. After confirming that the maternal blood pressure in Group L increased (an indicator of PE), Group L was further divided into two subgroups: one subgroup continued to receive only L-NAME (Group L, $n=7$ ), while the other subgroup (Group LT, $n=7$ ) received L-NAME with $0.08 \mathrm{mg} / \mathrm{mL}$ tadalafil (Cayman Chemical Company) suspended in $0.5 \% \mathrm{CMC}$, starting on 13 d.p.c. Tadalafil administration was continued until 17 d.p.c. The average dose of tadalafil was $19.3 \pm 1.3 \mathrm{mg} / \mathrm{kg} \mathrm{BW} /$ day. All dams were sacrificed on 17 d.p.c., and their placentas were harvested for further analysis.

Another set of dams was prepared following the same procedure described above (Group C, $n=4$; Group L, $n=5$ ) and sacrificed on 13 d.p.c. Their placentas were collected to evaluate the effect of L-NAME administration on mTOR signaling. Placentas for histological evaluation were fixed in $4 \%$ paraformaldehyde (Nacalai Tesque, Kyoto, Japan) in $0.2 \mathrm{M}$ sodium phosphate buffer (PBS) ( $\mathrm{pH} 7.4$ ) and then embedded in paraffin (Merck Ltd., Frankfurter, Germany) using standard procedures. Placentas for protein analysis were frozen in liquid nitrogen immediately after collection and stored at $-80{ }^{\circ} \mathrm{C}$ until further analysis.

\subsection{Fluorescent Immunohistochemical Staining}

The Paraffin blocks were sectioned at a thickness of $5 \mu \mathrm{m}$ and subjected to immunohistochemical analysis. For the evaluation of phosphorylated mTOR (p-mTOR), an antiphospho-mTOR (Ser2448) antibody (1:100, \#ab109268, Abcam, Cambridge, UK) was used as the primary antibody, and 4',6-diamidino-2-phenylindole (DAPI) was used for nuclear staining. Sections were incubated overnight at room temperature with the primary antibody, followed by an appropriate secondary antibody for $2 \mathrm{~h}$ at room temperature. Fluorescence images taken by FV1000-D IX81 confocal laser microscope (Olympus, Tokyo, Japan) were analyzed using Image J software (Wayne Rasband, National Institutes of Health, Bethesda, $\mathrm{MD}$, USA) to determine the percentage of p-mTOR-positive area in the labyrinth zone of the mouse placenta.

\subsection{Western Blotting}

Frozen mouse placenta was washed with PBS, and protein was extracted using radioimmunoprecipitation assay (RIPA) buffer (Nacalai Tesque, Kyoto, Japan). Bicinchoninic acid (BCA) assay was performed to quantify the isolated protein quantification using the Protein Assay BCA kit (Nacalai Tesque). Each sample containing $20 \mu \mathrm{g}$ of total protein was loaded into a well of polyacrylamide gel (ATTO, Tokyo, Japan) and subjected to Western blotting using standard procedures. Levels of 4E-BP1 and S6R were analyzed to assess the tadalafil effect on the downstream signaling of mTOR. For phosphorylation studies, we used Thr37/46 (1:5000, \#9459, Cell Signaling Technology, Danvers, MA, USA) and Thr70 (1:5000, \#9455, Cell Signaling Technology) for 4E-BP1 protein and Ser235/236 (1:5000, \#2211, Cell Signaling Technology) for S6R protein. For total (unphosphorylated and phosphorylated) protein detection of 4E-BP1 and S6R, we used 4E-BP1 antibody (1:5000, \#9452, Cell Signaling Technology) and S6R antibody (1:5000, \#2217, Cell Signaling Technology). Chemiluminescence detection was performed using HRP-conjugated secondary 
antibodies, and the developed blots were quantified using ImageJ software. $\beta$-actin (1:2000, \#sc-47778, Santa Cruz Biotechnology, Dallas, TX, USA) was used as a loading control for data normalization.

\subsection{Statistical Analyses}

All values are presented as mean \pm SE Statistical analyses were performed using GraphPad Prism7 (GraphPad, San Diego, CA, USA). The Student's t-test was used for two-group comparisons, and one-way ANOVA was used for three-group comparisons. A value of $p<0.05$ was considered statistically significant.

\section{Conclusions}

Tadalafil treatment improved placental mTOR signaling in L-NAME-induced FGR and PE mouse model. This study elucidates the first mechanistic insight into how tadalafil facilitates fetal growth in FGR mice and provides an important framework for future studies.

Author Contributions: Conceptualization, K.T., H.T. (Hiroaki Tanaka), and T.I.; formal analysis, K.T. and R.T.; investigation, K.T., R.T., K.Y., T.K., S.T., H.T. (Hiroki Takeuchi); resources, K.T., H.T. (Hiroaki Tanaka) and T.I.; data curation, K.T.; writing-original draft preparation, K.T.; writing-review and editing, H.T. (Hiroaki Tanaka).; visualization, K.T.; supervision, H.T. (Hiroaki Tanaka) and T.I.; project administration, K.T., H.T. (Hiroaki Tanaka) and T.I; funding acquisition, K.T., H.T. (Hiroaki Tanaka) and T.I. All authors have read and agreed to the published version of the manuscript.

Funding: This research was funded by the Kanzawa Medical Research Foundation (2019) and the Seiichi Imai Memorial Foundation (2020).

Institutional Review Board Statement: The study was conducted according to the guidelines of the Declaration of Helsinki and approved by the Mie University Animal Experiment Committee. (Approval code 273111, date of approval: 1 May 2020).

Informed Consent Statement: Patient consent was not applicable because the study did not involve humans.

Acknowledgments: We express our sincere thanks to Thomas Jansson and Fredrick J. Rosario for advising us on mTOR signaling research. We would also like to take this opportunity to thank Junzo Kigawa and Nao Omi for helping us with our experiments.

Conflicts of Interest: The authors declare no conflict of interest. The funders had no role in the study design; in the collection, analyses, or interpretation of data; in the writing of the manuscript; or in the decision to publish the results.

\section{References}

1. Pallotto, E.K.; Kilbride, H.W. Perinatal outcome and later implications of intrauterine growth restriction. Clin Obstet Gynecol. 2006, 49, 257-269. [CrossRef] [PubMed]

2. Dall'Asta, A.; Brunelli, V.; Prefumo, F.; Frusca, T.; Lees, C.C. Early onset fetal growth restriction. Matern Health Neonatol Perinatol. 2017, 3, 2. [CrossRef] [PubMed]

3. Heinonen, K.; Räikkönen, K.; Pesonen, A.K.; Andersson, S.; Kajantie, E.; Eriksson, J.G.; Wolke, D.; Lano, A. Behavioural symptoms of attention deficit/hyperactivity disorder in preterm and term children born small and appropriate for gestational age: A longitudinal study. BMC Pediatr. 2010, 10, 91. [CrossRef] [PubMed]

4. Murray, E.; Pearson, R.; Fernandes, M.; Santos, I.S.; Barros, F.C.; Victora, C.G.; Stein, A.; Matijasevich, A. Are fetal growth impairment and preterm birth causally related to child attention problems and ADHD? Evidence from a comparison between high-income and middle-income cohorts. J Epidemiol Community Health. 2016, 70, 704-709. [CrossRef]

5. Thornton, J.G.; Hornbuckle, J.; Vail, A.; Spiegelhalter, D.J.; Levene, M.; GRIT study group. Infant wellbeing at 2 years of age in the Growth Restriction Intervention Trial (GRIT): Multicentred randomized controlled trial. Lancet 2004, 364, 513-520. [CrossRef]

6. Lees, C.C.; Marlow, N.; van Wassenaer-Leemhuis, A.; Arabin, B.; Bilardo, C.M.; Brezinka, C.; Calvert, S.; Derks, J.B.; Diemert, A.; Duvekot, J.J.; et al. 2 year neurodevelopmental and intermediate perinatal outcomes in infants with very preterm fetal growth restriction (TRUFFLE): A randomised trial. Lancet 2015, 385, 2162-2172. [CrossRef]

7. Yoshikawa, K.; Umekawa, T.; Maki, S.; Kubo, M.; Nii, M.; Tanaka, K.; Tanaka, H.; Osato, K.; Kamimoto, Y.; Kondo, E.; et al. Tadalafil Improves L-NG-Nitroarginine Methyl Ester-Induced Preeclampsia With Fetal Growth Restriction-Like Symptoms in Pregnant Mice. Am J Hypertens. 2017, 31, 89-96. [CrossRef] 
8. Tachibana, R.; Umekawa, T.; Yoshikawa, K.; Owa, T.; Magawa, S.; Furuhashi, F.; Tsuji, M.; Maki, S.; Shimada, K.; Kaneda, M.K.; et al. Tadalafil treatment in mice for preeclampsia with fetal growth restriction has neuro-benefic effects in offspring through modulating prenatal hypoxic conditions. Sci Rep. 2019, 9, 234. [CrossRef]

9. Sekimoto, A.; Tanaka, K.; Hashizume, Y.; Sato, E.; Sato, H.; Ikeda, T.; Takahashi, N. Tadalafil alleviates preeclampsia and fetal growth restriction in RUPP model of preeclampsia in mice. Biochem Biophys Res Commun. 2020, 521, 769-774. [CrossRef]

10. Kubo, M.; Tanaka, H.; Maki, S.; Nii, M.; Murabayashi, N.; Osato, K.; Kamimoto, Y.; Umekawa, T.; Kondo, E.; Ikeda, T. Safety and dose-finding trial of tadalafil administered for fetal growth restriction: A phase-1 clinical study. J Obstet Gynaecol Res. 2017, 43, 1159-1168. [CrossRef]

11. Maki, S.; Tanaka, H.; Tsuji, M.; Furuhashi, F.; Magawa, S.; Kaneda, M.K.; Nii, M.; Tanaka, K.; Kondo, E.; Tamaru, S.; et al. Safety Evaluation of Tadalafil Treatment for Fetuses with Early-Onset Growth Restriction (TADAFER): Results from the Phase II Trial. J. Clin. Med. 2019, 8, 856. [CrossRef] [PubMed]

12. Gupta, M.B.; Jansson, T. Novel roles of mechanistic target of rapamycin signaling in regulating fetal growtht. Biol Reprod. 2019, 100, 872-884. [CrossRef] [PubMed]

13. Roos, S.; Jansson, N.; Palmberg, I.; Säljö, K.; Powell, T.L.; Jansson, T. Mammalian target of rapamycin in the human placenta regulates leucine transport and is down-regulated in restricted fetal growth. J Physiol. 2007, 582, 449-459. [CrossRef] [PubMed]

14. Peng, T.; Golub, T.R.; Sabatini, D.M. The immunosuppressant rapamycin mimics a starvation-like signal distinct from amino acid and glucose deprivation. Mol Cell Biol. 2002, 22, 5575-5584. [CrossRef]

15. Tee, A.R.; Blenis, J. mTOR, translational control and human disease. Semin Cell Dev Biol. 2005, 16, 29-37. [CrossRef]

16. Martin, D.E.; Hall, M.N. The expanding TOR signaling network. Curr Opin Cell Biol. 2005, 17, 158-166. [CrossRef]

17. Hay, N.; Sonenberg, N. Upstream and downstream of mTOR. Genes Dev. 2004, 18, 1926-1945. [CrossRef]

18. Jacinto, E.; Hall, M.N. Tor signalling in bugs, brain and brawn. Nat Rev Mol Cell Biol. 2003, 4, 117-126, correction appears in Nat Rev Mol Cell Biol. 2003, 4, 249. [CrossRef]

19. Laplante, M.; Sabatini, D.M. mTOR signaling in growth control and disease. Cell 2012, 149, 274-293. [CrossRef]

20. Rosario, F.J.; Gupta, M.B.; Myatt, L.; Powell, T.L.; Glenn, J.P.; Cox, L.; Jansson, T. Mechanistic Target of Rapamycin Complex 1 Promotes the Expression of Genes Encoding Electron Transport Chain Proteins and Stimulates Oxidative Phosphorylation in Primary Human Trophoblast Cells by Regulating Mitochondrial Biogenesis. Sci Rep. 2019, 9, 246. [CrossRef]

21. Roos, S.; Kanai, Y.; Prasad, P.D.; Powell, T.L.; Jansson, T. Regulation of placental amino acid transporter activity by mammalian target of rapamycin. Am J Physiol Cell Physiol. 2009, 296, C142-C150. [CrossRef] [PubMed]

22. Roos, S.; Lagerlöf, O.; Wennergren, M.; Powell, T.L.; Jansson, T. Regulation of amino acid transporters by glucose and growth factors in cultured primary human trophoblast cells is mediated by mTOR signaling. Am J Physiol Cell Physiol. 2009, 297, C723-C731. [CrossRef] [PubMed]

23. Rosario, F.J.; Kanai, Y.; Powell, T.L.; Jansson, T. Mammalian target of rapamycin signalling modulates amino acid uptake by regulating transporter cell surface abundance in primary human trophoblast cells. J. Physiol. 2013, 591, 609-625. [CrossRef] [PubMed]

24. Rosario, F.J.; Dimasuay, K.G.; Kanai, Y.; Powell, T.L.; Jansson, T. Regulation of amino acid transporter trafficking by mTORC1 in primary human trophoblast cells is mediated by the ubiquitin ligase Nedd4-2. Clin. Sci (Lond). 2016, 130, 499-512. [CrossRef]

25. Rosario, F.J.; Powell, T.L.; Jansson, T. Mechanistic target of rapamycin (mTOR) regulates trophoblast folate uptake by modulating the cell surface expression of FR- $\alpha$ and the RFC. Sci Rep. 2016, 6, 31705. [CrossRef]

26. Dimasuay, K.G.; Boeuf, P.; Powell, T.L.; Jansson, T. Placental Responses to Changes in the Maternal Environment Determine Fetal Growth. Front. Physiol. 2016, 7, 12. [CrossRef]

27. Yung, H.W.; Calabrese, S.; Hynx, D.; Hemmings, B.A.; Cetin, I.; Charnock-Jones, D.S.; Burton, G.J. Evidence of placental translation inhibition and endoplasmic reticulum stress in the etiology of human intrauterine growth restriction. Am. J. Pathol. 2008, 173, 451-462. [CrossRef]

28. Chen, Y.Y.; Rosario, F.J.; Shehab, M.A.; Powell, T.L.; Gupta, M.B.; Jansson, T. Increased ubiquitination and reduced plasma membrane trafficking of placental amino acid transporter SNAT-2 in human IUGR. Clin. Sci (Lond). 2015, 129, 1131-1141. [CrossRef]

29. Hung, T.H.; Hsieh, T.T.; Wu, C.P.; Li, M.J.; Yeh, Y.L.; Chen, S.F. Mammalian target of rapamycin signaling is a mechanistic link between increased endoplasmic reticulum stress and autophagy in the placentas of pregnancies complicated by growth restriction. Placenta 2017, 60, 9-20. [CrossRef]

30. Chassen, S.; Jansson, T. Complex, coordinated and highly regulated changes in placental signaling and nutrient transport capacity in IUGR. Biochim Biophys Acta Mol. Basis Dis. 2020, 1866, 165373. [CrossRef]

31. Kavitha, J.V.; Rosario, F.J.; Nijland, M.J.; McDonald, T.J.; Wu, G.; Kanai, Y.; Powell, T.L.; Nathanielsz, P.W.; Jansson, T. Downregulation of placental mTOR, insulin/IGF-I signaling, and nutrient transporters in response to maternal nutrient restriction in the baboon. FASEB J. 2014, 28, 1294-1305. [CrossRef]

32. Rosario, F.J.; Schumacher, M.A.; Jiang, J.; Kanai, Y.; Powell, T.L.; Jansson, T. Chronic maternal infusion of full-length adiponectin in pregnant mice down-regulates placental amino acid transporter activity and expression and decreases fetal growth. J. Physiol. 2012, 590, 1495-1509. [CrossRef]

33. Fushima, T.; Sekimoto, A.; Minato, T.; Ito, T.; Oe, Y.; Kisu, K.; Sato, E.; Funamoto, K.; Hayase, T.; Kimura, Y.; et al. Reduced Uterine Perfusion Pressure (RUPP) Model of Preeclampsia in Mice. PLoS One 2016, 11, e0155426. [CrossRef] [PubMed] 
34. Bakrania, B.A.; George, E.M.; Granger, J.P. Animal models of preeclampsia: Investigating pathophysiology and therapeutic targets. Am. J. Obstet Gynecol. 2020. [CrossRef]

35. Rotella, D.P. Phosphodiesterase 5 inhibitors: Current status and potential applications. Nat. Rev. Drug Discov. 2002, 1, 674-682. [CrossRef] [PubMed]

36. França, M.E.R.; Ramos, R.K.L.G.; Oliveira, W.H.; Duarte-Silva, E.; Araújo, S.M.R.; Lós, D.B.; Peixoto, C.A. Tadalafil restores long-term memory and synaptic plasticity in mice with hepatic encephalopathy. Toxicol Appl Pharmacol. 2019, $379,114673$. [CrossRef] [PubMed]

37. Gresser, U.; Gleiter, C.H. Erectile dysfunction: Comparison of efficacy and side effects of the PDE-5 inhibitors sildenafil, vardenafil and tadalafil-review of the literature. Eur J. Med. Res. 2002, 7, 435-446. [PubMed]

38. Ghofrani, H.A.; Voswinckel, R.; Reichenberger, F.; Olschewski, H.; Haredza, P.; Karadaş, B.; Schermuly, R.T.; Weissmann, N.; Seeger, W.; Grimminger, F. Differences in hemodynamic and oxygenation responses to three different phosphodiesterase-5 inhibitors in patients with pulmonary arterial hypertension: A randomized prospective study. J. Am. Coll Cardiol. 2004, 44, 1488-1496. [CrossRef]

39. Barroso, F.; Ribeiro, J.C.; Miranda, E.P. Phosphodiesterase Type 5 Inhibitors and Visual Side Effects: A Narrative Review. J. Ophthalmic Vis. Res. 2021, 16, 248-259. [CrossRef]

40. Saenz de Tejada, I.; Angulo, J.; Cuevas, P.; Fernández, A.; Moncada, I.; Allona, A.; Lledó, E.; Körschen, H.G.; Niewöhner, U.; Haning, H.; et al. The phosphodiesterase inhibitory selectivity and the in vitro and in vivo potency of the new PDE5 inhibitor vardenafil. Int J. Impot Res. 2001, 13, 282-290. [CrossRef]

41. Sharp, A.; Cornforth, C.; Jackson, R.; Harrold, J.; Turner, M.A.; Kenny, L.C.; Baker, P.N.; Johnstone, E.D.; Khalil, A.; von Dadelszen, P.; et al. Maternal sildenafil for severe fetal growth restriction (STRIDER): A multicentre, randomised, placebocontrolled, double-blind trial. Lancet Child. Adolesc Health. 2018, 2, 93-102. [CrossRef]

42. Groom, K.M.; McCowan, L.M.; Mackay, L.K.; Lee, A.C.; Gardener, G.; Unterscheider, J.; Sekar, R.; Dickinson, J.E.; Muller, P.; Reid, R.A.; et al. STRIDER NZAus: A multicentre randomised controlled trial of sildenafil therapy in early-onset fetal growth restriction. BJOG. 2019, 126, 997-1006. [CrossRef] [PubMed]

43. Pels, A.; Derks, J.; Elvan-Taspinar, A.; van Drongelen, J.; de Boer, M.; Duvekot, H.; van Laar, J.; van Eyck, J.; Al-Nasiry, S.; Sueters, M.; et al. Maternal Sildenafil vs Placebo in Pregnant Women With Severe Early-Onset Fetal Growth Restriction: A Randomized Clinical Trial. JAMA Netw Open. 2020, 3, e205323. [CrossRef] [PubMed] 